\title{
Sarau Palavra Encantada no Bar Cantinho Cirassol: um espaço cultural na periferia da cidade de Sorocaba
}

\section{Sarau Enchanted Word at the Little Corner Sunflower: a cultural space on the outskirts of the city of Sorocaba}

https://doi.org/10.34112/2317-0972a2020v38n80p65-79

\author{
Marco Aurélio Nunes de Oliveira ${ }^{1}$ \\ Dulcinéia de Fátima Dulce Ferreira² \\ Kelen Christina Leite ${ }^{3}$
}

RESUMO: Neste artigo discutimos a cidade contemporânea e sua periferia; abordamos a penetração do capital em todas as esferas da vida e a expansão de um determinado padrão de consumo, bem como sua consequência na vida das pessoas. Apresentamos a cidade de Sorocaba, o bairro Wanel Ville, o bar Cantinho Girassol, a biblioteca comunitária e o Sarau Palavra Encantada. Por meio de um estudo de caso mergulhamos no Sarau Palavra Encantada, uma experiência cultural na Periferia de Sorocaba, interior do Estado de São Paulo, fruto de uma pesquisa de mestrado em educação, junto ao PPGEd UFSCarSorocaba, realizada entre os anos de 2016 e 2018.

PALAVRAS-CHAVE: Experiência cultural; sarau; periferia; cidade.

ABSTRACT: In this article we discuss the contemporary city and its periphery; we approach the penetration of capital in all spheres of life and the expansion of a certain pattern of consumption, as well as its consequence in people's lives. We present the city of Sorocaba, the Wanel Ville neighborhood, the Cantinho Girassol bar, the community library and the Sarau Palavra Encantada. Through a case study, we immersed ourselves in Sarau Palavra Encantada, a cultural experience in the outskirts of Sorocaba, in the interior of the State

1. Universidade Federal de São Carlos, Sorocaba, São Paulo, Brasil.

2. Universidade Federal de São Carlos, Sorocaba, São Paulo, Brasil.

3. Universidade Federal de São Carlos, Sorocaba, São Paulo, Brasil. 
of São Paulo, as a result of a master's research in education, at PPGEd UFSCar-Sorocaba, carried out between 2016 and 2018.

KEYWORDS: Cultural experience; sarau; periphery; city.

\section{INTRODUÇÃO}

Este artigo é fruto de uma pesquisa realizada em um bar da periferia de Sorocaba, no bairro Wanel Ville I, o "Cantinho Girassol”, que abriga o Sarau Palavra Encantada há sete anos. A pesquisa esteve vinculada ao Programa de Pós-Graduação em Educação da UFSCar, campus Sorocaba (PPGed-UFSCar-Sorocaba, linha “Educação, Comunidade e Movimentos Sociais"). Tivemos como objetivo acompanhar e analisar o Sarau Palavra Encantada, procurando identificar a potência de vida presente nesta experiência.

Trata-se de um estudo de caso que se apoiou na ideia de pesquisa participante (BRANDÃO, 1983). Para tanto, realizamos uma revisão bibliográfica em torno de questões urbanas e de experiências culturais na periferia. Acompanhamos o cotidiano do bar e as atividades culturais aos finais de semana; também realizamos onze entrevistas semiestruturadas com participantes do Sarau e/ou frequentadores do bar - trouxemos para a conversa alguns desses personagens, que serão apresentados à medida em que forem convocados a ocupar o palco neste artigo. Com este estudo, podemos afirmar que o Sarau Palavra Encantada, que acontece no bar Cantinho Girassol, configura-se como um espaço contra-hegemônico à lógica do capital.

1. DE ONDE VEM A CIDADE?

A cidade não pára, a cidade só cresce O de cima sobe e o de baixo desce A cidade não pára, a cidade só cresce O de cima sobe e o de baixo desce

CHICO SCIENCE

Para o historiador Jacques Le Goff (1998), as cidades medievais tiveram um importante papel no desenvolvimento da civilização europeia, pois funcionaram também como espaço de trocas, onde as pessoas se encontravam e socializavam os conhecimentos. A cidade medieval também funcionava como espaço de festa, 
onde os citadinos se encontravam pelo simples prazer de se encontrar e celebrar; ainda de acordo com Le Goff, nesse período ela se converte em espaço de cobiça.

Nesse processo, Marx irá demarcar que "a burguesia submeteu o campo à cidade. Criou grandes centros urbanos; aumentou prodigiosamente a população das cidades em relação à dos campos (... ) dos servos da Idade Média nasceram os moradores dos primeiros burgos; desta população municipal, saíram os primeiros elementos da burguesia” (MARX; ENGELS 2005, p. 41- 44). Novamente Le Goff:

A cidade da idade média é uma sociedade abundante, concentrada em um pequeno espaço, um lugar de produção e de trocas em que se mesclam o artesanato e o comércio alimentados por uma economia monetária [...]. Mas a cidade concentra também os prazeres, os da festa, os dos diálogos na rua, nas tabernas, nas escolas, nas igrejas e mesmo nos cemitérios. Uma concentração de criatividade de que é testemunha a jovem universidade que adquire rapidamente poder e prestígio, na falta de uma plena autonomia (LE GOFF, 1998, p. 25).

A expropriação dos camponeses enche a cidade de despossuídos em busca de trabalho nas indústrias. Dessa forma, a urbanização e a industrialização caminham juntas em um processo indutor e induzido, em que tanto a primeira favorece a segunda quanto vice-versa (LEFEBVRE, 2001). Nesse contexto, tanto as fábricas precisam da concentração de pessoas, alimentando ainda o sistema com um aumento do exército de reserva, quanto a massa de despossuídos que se concentra nos grandes centros precisa dos salários pagos pelos empregadores para garantir suas mínimas condições de subsistência.

Lefebvre (1999) argumenta que a cidade nasce como uma obra que retrata a singularidade do modo de vida de seus habitantes. Com a chegada do comércio e posteriormente da indústria, esse modelo de cidade até aqui comentado se implode. Com a consolidação e o crescimento das indústrias, um modo de cidade como produto vai nascendo e se espraia para o mundo todo. Esse novo modo de organização do espaço vai se distanciando do retrato de uma obra humana e se configurando como produto do capital.

As cidades tomaram proporções colossais, com estruturas e características muito mais complexas. De acordo com Lefebvre (1999, p. 49): "Atualmente o fenômeno urbano surpreende por sua enormidade; sua complexidade ultrapassa os meios do conhecimento e os instrumentos da ação prática”. 
Sarau Palavra Encantada no Bar Cantinho Girassol: um espaço cultural na...

2. “Cidade maravilhosa Cheia de encantos mil”

Sorocaba é uma cidade do interior do estado de São Paulo, localizada a aproximadamente cem quilômetros da capital. No idioma tupi, Sorocaba significa Terra Rasgada; é uma cidade com perfil industrial e figura entre as mais ricas do estado e do país. De acordo com o $\mathrm{IBGE}^{4}$, ela tem aproximadamente 687.357 mil habitantes e a renda média dos trabalhadores em empregos formais é de 3,2 salários-mínimos; a cidade conta com 203 estabelecimentos de ensino fundamental e 95 de nível médio, envolvendo escolas públicas e privadas. A taxa de escolarização dos jovens de 6 a 14 anos é de 98,1\%.

Como já mencionado, as cidades contemporâneas aparecem como magníficas obras do capital, cobertas por arranha-céus, shoppings e avenidas tomadas por utilitários. No entanto, todos esses baluartes escondem uma cidade fragmentada e segregada. Em Sorocaba, embora de forma tardia, essa dinâmica de fragmentação e segregação do espaço se manifestará de forma semelhante aos grandes centros urbanos.

De acordo com Burgos (2015, p. 155), "a cidade [de Sorocaba] vem ampliando o número de shopping centers, chegando ao número de nove empreendimentos em 2014”. Ainda de acordo com a autora, a frota de automóveis e os empreendimentos imobiliários também aumentaram significativamente. Sorocaba é uma cidade em processo de expansão, orientada pela lógica neoliberal e orquestrada pelas demandas do capital.

Esta cidade carrega consigo o conflito entre diversas formas de resistência e uma hegemonia conservadora. Auro Moreno Romero, professor de Geografia da rede pública do estado de São Paulo, morador do bairro Wanel Ville e frequentador do bar Cantinho Girassol, não se apresenta no Sarau. Costuma frequentar o Espaço Cultural para tomar uma cerveja e levar uma prosa no Balcão. Assume o palco neste artigo e diz:

Eu acho que o sorocabano é menos tolerante, em relação ao que é diferente, ao que é diverso, do que o cara que mora numa cidade como São Paulo, que tem muito mais o conceito de uma cidade cosmopolita, que não dorme, que está sempre em movimento, que tem mais teatros, mais cinemas. Então Sorocaba é muito restrita. Quantas salas de cinemas e teatros você tem em Sorocaba? Acho que uma, duas no máximo! O máximo que você vê aqui são uns shows de artistas sertanejos, por exemplo. Então, acho que falta na cidade essa mistura que é o que vai transformar o lugar, num lugar melhor, com mais respeito. Acho que o sorocabano, até pelas eleições, por quem ele

4. https://cidades.ibge.gov.br/brasil/sp/sorocaba/panorama - Acesso em: 2/12/2020. 
elege, é muito conservador ainda. Então você ter um espaço em que as pessoas possam conversar, dialogar, e isso na periferia ainda, é um avanço enorme pra cidade (AURO, In: OLIVEIRA, 2016, p. 89).

\subsection{POR FORA DA CIDADE, A PERIFERIA VISTA POR DENTRO}

Enquanto as cidades no período da Baixa Idade Média eram cercadas por muralhas, as cidades de hoje não são divididas por muros, embora cada vez mais nos defrontemos com a existência de condomínios fechados, mas a divisão mais explícita se encontra na relação complexa entre o centro e a periferia da cidade. Tomamos como periferia,

(...) os territórios em presença do Urbano Periférico, no qual sobrevive o trabalhador que sobra dos mais diversos setores, absorvido em processos de trabalho existentes no circuito inferior da economia urbana, que se vincula direta ou indiretamente ao circuito superior (BURGOS, 2013, p. 264).

A temática da periferia tem ocupado a pauta da grande mídia nos últimos vinte anos. Ora ela aparece de forma estereotipada, associada ao crime e à violência, ora de forma romantizada, a partir do que são enfatizados os aspectos de solidariedade, resiliência e determinação, de forma a ocultar as contradições (NASCIMENTO, 2011).

É importante destacar que a periferia, embora não evidencie sempre em suas paisagens a mesma falta de infraestrutura de anos atrás, carrega ainda a falta e/ou precariedade dos empregos, a violência, a ausência de equipamentos públicos de saúde, cultura, lazer e entretenimento (BURGOS, 2013).

Ao falarmos sobre a relação cidade, periferia e cultura, nos deparamos com alguns autores, poetas e compositores que abordam a questão da diversidade e do conflito nos grandes centros. "A cidade contemporânea (...) longe de ser o lugar da homogeneidade cultural vem marcada pelo encontro - e pelo conflito - de diferentes grupos" (THOMAZ, 1995, p. 427). Como podemos constatar na fala de Canto:

As grandes periferias do Brasil, bares e igrejas podem ser encontrados em quase todas as esquinas, e o mais inusitado é que, muitas vezes, estão separados apenas por uma única parede. A cultura? Bem, essa quase sempre está do lado de lá, depois da ponte (gíria usada por poetas das periferias, quando se trata de situar geograficamente 
Sarau Palavra Encantada no Bar Cantinho Girassol: um espaço cultural na...

os bairros onde moram). Nas periferias não há museus nem teatros, e as bibliotecas contam-se nos dedos. Nesse cenário, o que ninguém esperava é que a poesia e suas vertentes fossem nascer (e dar ótimos frutos) justamente naquele boteco da esquina. No Campo Limpo, por exemplo, a segunda-feira veste-se de vermelho e vem com força total. É o Sarau do Binho - uma referência no bairro - que, há oito anos, reúne poetas, escritores, intelectuais e uma boa parcela da própria comunidade. Na ocasião, muitos expressam suas ideias por meio de diversas linguagens artísticas. É um intercâmbio cultural! (CANTO, 2016, s/p).

Neste trabalho analisamos uma experiência cultural na periferia de Sorocaba, uma cidade de médio porte. Não tratamos a periferia, nem tampouco as experiências das pessoas que ali vivem, como se fossem insignificantes, mas, ao contrário, procuramos identificar e revelar as potencialidades e especificidades ali presentes.

Para qualquer desavisado que chegue à cidade de Sorocaba e apenas circule de carro pelas principais avenidas, a impressão que fica é a de uma cidade rica e opulenta. No entanto, há contradições implícitas, e muitas vezes explícitas, no conteúdo da urbe sorocabana, sobretudo nas periferias.

Talvez o maior drama da periferia sorocabana seja como o de outras periferias: o abandono e a falta de políticas públicas voltadas para cultura, saúde e lazer. Aqui, como em outras periferias, quase não há espaços para encontros que não sejam o bar e a igreja. Não há bibliotecas, tampouco teatros, cinemas ou qualquer coisa do gênero. As praças públicas, quando existem, não funcionam como local de encontro. Raras são as vezes que recebem alguma atividade promovida pela Secretaria da Cultura, e quando isso acontece geralmente ocorre dentro da lógica do grande evento.

Sorocaba é uma cidade grande, uma população grande também. Só que Sorocaba não é uma cidade que a gente poderia caracterizar como cosmopolita. Ou seja, não tem aquele pulsar cultural, não tem lugares que você pode ir... A não ser que você tenha dinheiro. Então é uma cidade que embora seja grande, ela não tem grandes lugares que podem apresentar para você lazer, cultura, divertimento, bom papo. Então, ou você paga para frequentar ambientes mais caros, mais sofisticados, ou você tem que procurar um lugar que te ofereça o mínimo de cultura, de papo bom, de gente que converse legal e a um baixo custo (AURO, In: OLIVEIRA, 2016, p. 88). 
O que podemos dizer é que as sucessivas gestões da oligarquia local implementaram o espraiamento da cidade, ou seja a expansão da cidade segundo a lógica do capital, fomentando seu crescimento sem, no entanto, comprometer-se com as questões sociais. Essa é uma tendência no processo de urbanização brasileiro que se faz presente também em uma cidade de médio porte como Sorocaba.

\subsection{O bairro Wanel Ville}

Wanel Ville é um bairro situado na periferia de Sorocaba, fruto do processo de expansão imobiliária, na zona oeste da cidade, no início dos anos 2000. De acordo com o site do grupo responsável pelos empreendimentos nessa região, o bairro possui seis mil lotes.

É um bairro bastante estruturado, com ciclovia, posto de saúde, estabelecimentos comerciais. No entanto, um olhar mais atento permitirá ao observador notar que, assim como em outras periferias, a cultura não tem seu espaço garantido.

\subsection{No Wanel Ville, o Bar Cantinho Girassol}

Embora o processo de expansão e reprodução da cidade a partir da lógica do capital ${ }^{5}$ promova a coisificação e o isolamento dos habitantes, a vida das pessoas se modifica com a mesma rapidez com que se reproduz a cidade, mas sempre há um processo inverso de resistência, baseado na solidariedade, nas trocas e na ajuda mútua (ROLNIK, 1988).

É nesta periferia de Sorocaba que surge o bar Cantinho Girassol, de propriedade de Zé Miranda, um migrante natural de Irecê-BA, que passou a maior parte de sua vida na Grande São Paulo, trabalhando no setor de bares, aos quais sempre buscou dar um caráter cultural. Há alguns anos, veio a Sorocaba em busca de uma cidade mais calma, e nela se tornou proprietário do Cantinho Girassol e criador do Sarau Palavra Encantada.

(... ) fiquei 15 anos trabalhando com esse bar, com eventos culturais lá em SP, até que um dia resolvi vir para o interior, procurar uma cidade mais tranquila para viver né, mas sempre com a ideia da cultura na cabeça, de trabalhar essa parte, aí chegamos

5. "As catedrais, apesar de construídas pelo homem, pertencem a Deus; já as cidades de hoje, pertencem ao capital. Para usufruir a primeira é necessário a subjugação a Deus, seguir seus mandamentos. No caso da cidade é a subjugação do homem às necessidades de reprodução do capital; onde o homem se vê capturado pelas necessidades de consumo e lazer" (CARLOS, 2013, p. 12). 
Sarau Palavra Encantada no Bar Cantinho Girassol: um espaço cultural na...

em Sorocaba, procuramos um barzinho para a gente comprar né, que tenha a característica da gente que sempre é trabalhar na periferia, para tentar incentivar a cultura onde ela não chega, é mais difícil de chegar. Aí até que procuramos vários bares aqui em Sorocaba, em regiões mais centrais assim, mas não era nossa característica, até que encontramos este aqui no Wanel Ville, onde a gente também, já logo de início, já tentamos implantar a ideia da cultura, criando uma biblioteca no bar, e trazendo um pessoal, já começou a encostar um pessoal bem ligado à cultura da cidade também (ZÉ MIRANDA, In: OLIVEIRA, 2016, p. 141).

No bar de São Paulo chamado Pioneiros do Brás ele se inspirava na Cooperifa ${ }^{6}$, de Sérgio Vaz. Ele conta que

(... ) lá em São Paulo, existem aí, vários locais que fazem esse tipo de trabalho, principalmente em bares né. Temos, lá, a fonte de inspiração. Minha maior é o poeta Sérgio Vaz, que é um poeta da periferia. É um cara que também trabalhava em bar, durante muito tempo ele trabalhou em bar com o pai dele, e sempre gostava de ler também, é o meu caso também (...) o Sarau da Cooperifa, que o Sérgio Vaz criou uma cooperativa. Cooperifa é a Cooperativa da Periferia. Entendeu? E a gente sempre acompanhou esse trabalho do Sérgio Vaz né, eu sempre acompanhei, a gente participava de Saraus, inclusive quando começamos a fazer os Saraus lá no Pioneiro do Brás, começou a vir os poetas da periferia lá da Cooperifa né. Poetas fantásticos, aí começou a se apresentar também lá no Sarau da Amizade, que é o que a gente fazia lá no Brás, chamava Sarau da Amizade. Aí começou a vir os poetas da cooperifa, eu já admirava bem o trabalho do Sérgio Vaz, e é o que eu coloco aqui, a inspiração veio daí, do Sérgio Vaz. Aí tem o Binho, aí tem um monte de bares que fazem este tipo de Sarau né. O diferencial do que eu faço, é que, no do Sérgio Vaz, tem um poeta por trás, o Binho é escritor também; dono de bar, mas é escritor e jornalista, o Sérgio Vaz também, e eu sou um cara comum, que não tem nenhuma formação universitária, sou apenas um admirador dos caras, e pus em prática a ideia deles (ZÉ MIRANDA, In: OLIVEIRA, 2016, p. 142).

O bar Cantinho Girassol já nasce como uma experiência cultural, e assim confirma que como as flores brotam do concreto, uma experiência cultural pode surgir na periferia.

6. Um evento cultural (Sarau) que acontece há mais de 10 anos no bar do Zé Batidão, localizado na R. Bartolomeu dos Santos, 797 - Jardim Guarujá - Periferia, São Paulo/ SP, é coordenado pelo poeta Sérgio Vaz. 
O olhar atento ao modesto barzinho na periferia de Sorocaba revela as potencialidades e possibilidades que emanam do "nível do habitar" (LEFEBVRE, 1999). As redes de associação e solidariedade entre os periféricos aparecem, não como algo cristalizado, mas de forma dinâmica, revelando também os conflitos, as contradições e as dissidências. Nas palavras de Auro:

E o bar aqui oferece uma música de qualidade, oferece pessoas que tem uma cabeça legal, que conseguem debater, que conseguem discutir. Discutir em alto nível: as pessoas que frequentam o bar não são os bebuns que a gente está acostumado a encontrar por aí. Então você acaba aliando duas coisas. Primeiro: encontrar pessoas que você possa conversar sobre assuntos diversos, se divertir e, ainda, ter um lazer e contato com a música, poesia, um livro e assim por diante (AURO, In: OLIVEIRA, 2016, p. 88).

Logo que Zé Miranda comprou o bar Cantinho Girassol, realizou algumas mudanças no layout do espaço e contratou um artista plástico para fazer um grafite na parede, com o rosto e uma frase de Raul Seixas. Na sequência, começou a colocar livros no espaço. Essas atitudes atraíram para o bar um público diferente, mais ligado à área da cultura.

A Biblioteca Comunitária foi montada sem grandes burocracias. Zé Miranda trouxe para o bar os livros que tinha, arranjando-os pelo ambiente, de modo que ficassem à vista dos frequentadores e passou a explicar-lhes a proposta e a dinâmica da Biblioteca Comunitária. A ideia era de que os frequentadores a alimentassem com doações e que fizessem os empréstimos sem nenhuma burocracia, com base na confiança. Aqui trazemos para a conversa Vadson, funcionário dos Correios, morador do bairro, frequentador do bar e do Sarau. Ele diz que "logo de início a gente não conhecia muito [a ideia]. Mas aí depois a gente já começou a ver livros por aqui, eu mesmo fiz algumas doações de livros, trouxe uma coleção de livros aqui. Aí começou a aumentar" (VADSON, In: OLIVEIRA, 2016, p. 135).

Hoje, a Biblioteca funciona muito bem; os frequentadores compreenderam a dinâmica. Com algumas exceções, Zé Miranda não tem problemas com o empréstimo dos livros. Apenas quando percebe que alguém está levando muitos livros e não está repondo é que ele intervém, limitando a retirada de material. Mas, de acordo com ele mesmo, são raras as ocasiões em que isso ocorre. 
Sarau Palavra Encantada no Bar Cantinho Girassol: um espaço cultural na...

2.4. No Bar Cantinho Girassol, o Sarau Palavra Encantada

Todo sujeito é livre para conjugar o verbo que quiser

Todo verbo é livre para ser direto e indireto

Nenhum predicado será prejudicado

Nem a frase, nem a crase e ponto final!

Fernando Anitelli - O Teatro Mágico

Após a criação da Biblioteca Comunitária, em 2012, surgiu a proposta de realizar um Sarau no bar, como também ocorria em São Paulo. Zé Miranda disponibilizou o espaço para a realização do Sarau, que inicialmente foi organizado pelo poeta Córdoba Jr. e pelo professor Antônio Paulo. O sarau nasceu em 2013 e foi batizado de Sarau Palavra Encantada, um espaço aberto a poetas, músicos e artistas em geral.

O Sarau Palavra Encantada aparece como importante espaço de acolhimento de artistas que buscam um lugar para socializar sua arte, e ainda como elemento político e modificador das pessoas, uma vez que promove o encontro e a socialização de saberes, de conhecimento e de arte.

O poeta e professor de informática Evandro Aranha, que se apresenta no espaço e já realizou o lançamento de dois livros no Sarau Palavra Encantada, afirma:

O Girassol acredito que tem uma função, primeiramente, de cidadania e de ocupação do espaço público, porque ele ocupa. Esse movimento aqui do Girassol, ele é um movimento que mostra que a cultura não tem que ficar trancafiada em biblioteca, em museu. Ele mostra que um bar na periferia pode prestar esse papel de ser um agente público modificador das pessoas. Além da parte cidadã, também é um ato político, porque a arte é política (...)

(...) Foi o lugar que eu me descobri, porque antigamente eu achava que eu escrevia poesia para mim. A partir do momento que vim aqui, o pessoal foi receptivo, foi acolhedor, eu descobri que a poesia tinha uma função muito maior do que satisfazer meu ego. Era uma coisa que alguém podia realmente ouvir o que eu estava falando, podia acreditar naquilo, sentir alguma coisa diferente. $\mathrm{E}$ aqui, pelo fato de ser um bar receptivo, os donos darem total liberdade, apoio mesmo, cultural à arte, me fez assim praticamente... aqui eu brinco com o Zé: aqui é minha segunda casa (EVANDRO ARANHA, In: OLIVEIRA, 2016, p. 73). 
Encontrar pessoas e socializar alegrias e angústias é uma atividade cada vez mais difícil na sociedade de consumo em que vivemos. O Cantinho Girassol funciona normalmente durante a semana como um típico bar de periferia, mas aos finais de semana - sextas e sábados - é palco de atividades culturais como o Sarau Palavra Encantada, por onde já passaram diversos artistas de várias cidades, além de um público específico que frequenta semanalmente os eventos culturais.

O Sarau acolhe artistas que não têm onde apresentar seu trabalho, oferece possibilidades de encontros e socialização e favorece o desenvolvimento e o aprendizado das pessoas que frequentam o espaço. É um lugar de fundamental importância para seus frequentadores, conforme a entrevista do Poeta Córdoba Jr, pseudônimo de João Batista Tomazi, funcionário dos Correios aposentado, fundador e frequentador do Sarau Palavra Encantada:

Tem uma magia diferente, uma magia especial aqui no Cantinho. É meio difícil até de explicar. Pra você ver: o Bosco, mesmo, falou outro dia que ele também se sente assim e quando sai daqui, sai de maneira diferente. O Cantinho é isso: você vem aqui não querendo nada, acaba se espairecendo, tendo uma alegria muito grande de participar do sarau, dos dias de música (CORDOBA JR., In: OLIVEIRA, 2016, p. 74).

Para Vadson, o espaço tem uma significância especial. Trata-se de um lugar onde ele se sente confortável, a ponto de trazer a família (sua esposa). Também aprecia as atividades culturais que lá ocorrem:

No início era mais poesia, aí depois começou a ter, também, música. E o bom é a diversidade que tem: tem teatro, tem cinema, tem música. Então é um espaço que você pode ver de tudo num único local. Isso que é importante. Inclusive eu trouxe minha esposa pra cá, que nunca tinha frequentado aqui o bar, tornou-se amiga de praticamente todo o pessoal aqui. Ela participa do sarau, ela recita poesias, ela gosta muito (VADSON, In: OLIVEIRA, 2016, p. 87).

Dentre os entrevistados, Vadson foi um dos que apontaram o Sarau Palavra Encantada como Resistência, assim como Zé Miranda. Embora reconheça o caráter de entretenimento, nas palavras de Auro é possível perceber que o Cantinho Girassol vai além do que ocorre aos sábados. 
Sarau Palavra Encantada no Bar Cantinho Girassol: um espaço cultural na...

Então eu vejo o bar não apenas como um lugar de lazer, mas um lugar que pode resistir a um sistema comercial de cultura, onde poucas pessoas têm acesso. Então o bar representa, principalmente por estar situado numa periferia, uma possibilidade, uma alternativa de a pessoa encontrar algo diferenciado (AURO, In: OLIVEIRA, 2016, p. 88).

Ana Cristina (Aninha) frequenta o espaço desde os nove anos de idade, acompanhada pelos seus pais. Declamou pela primeira vez no Sarau o poema "Menininha”, de Vinícius de Moraes, depois passou a declamar poemas de sua própria autoria. Hoje, já tem quatro livros publicados, sendo três de poesia e um de prosa.

(...) o primeiro lugar que eu declamei, que eu declamo até hoje é o Cantinho. No começo eu declamava poesias de outros autores, até que um dia eu criei coragem e declamei uma poesia minha. Desde então eu não paro mais. [...]. Sim, eu já lancei três livros. O Sementes de Ana Cristina em fevereiro de 2015, Flores de Ana Cristina em fevereiro de 2016, e Frutos de Ana Cristina agora em Fevereiro de 2017. [...]. Foram muitas pessoas que eu conheci aqui, que acabaram me passando a experiência, quando eu vinha aqui no Cantinho e declamava minhas poesias. Quando eu ouvia as poesias de outros autores também, eu tinha uma convivência com outros poetas, então isso acabou contribuindo mais ainda com esse amadurecimento, cada conversa, cada história que eu ouvia, tudo isso contribuiu com o amadurecimento poético (ANA CRISTINA, In: OLIVEIRA, 2016, p. 100).

Ao realizarmos a pesquisa que aqui compartilhamos, encontramos elementos que evidenciam a importância e o potencial de espaços como o aqui apresentado. Pudemos identificar que eles podem promover encontros cheios de possibilidades de vida, sobretudo nas periferias, onde o abandono cultural se faz tão presente.

\section{CONSIDERAÇÕES FINAIS}

Bar também é cultura sim! A Biblioteca Comunitária do Cantinho Girassol funciona como elemento disseminador da cultura no bairro Wanel Ville I; é uma resposta clara dos cidadãos à ausência de estruturas do poder público, que insiste em manter tão longe do povo o acesso à cultura e ao entretenimento.

É claro que Zé Miranda, o idealizador do Sarau Palavra Encantada, não está sozinho nesse processo; com ele, há várias pessoas que atuam cotidianamente para que 
essa experiência continue viva; além disso, Zé Miranda também não está isolado, pois além do Sarau Palavra Encantada e da Biblioteca comunitária há outros focos de resistência à massificação e à domesticação para o consumo na cidade.

Bar é encontro sim! As pessoas que frequentam o Cantinho Girassol explicitaram a importância de ter um espaço que seja um lugar que signifique algo. Um lugar que ajudam a construir através da solidariedade entre os participantes, da arte, da cultura, das trocas, e dos conflitos. Sobretudo, um lugar que podem chamar de seu, com o qual estabelecem uma relação de afeto e pertencimento.

O lugar de encontro favorece a troca de saberes, experiências, frustrações, dificuldades, e por que não, de discordâncias. Para que as pessoas dialoguem, componham, discutam e até mesmo briguem, primeiro é preciso que as pessoas se encontrem, e é isso que as pessoas fazem no Cantinho Girassol, as pessoas se encontram e trocam, se reconhecem como humanos.

Mas trocam o quê? As pessoas trocam tudo aquilo que acumularam ao longo da vida; o "meio grito" (BRANDÃO, 1984) que se esconde pode finalmente sair e tornar-se "um grito inteirado" (ibdem).

Por fim, é importante dizer que bar é ego, é briga, é disputa, é dificuldade, é vida, como diz a canção de Gilberto Gil; "Vida é alegria / Vida me dá prazer / Vida é a luz do dia /Vida vadia /Vida é o amor / Vida é cor e confusão / Vida é som e paixão / Vida é alegria / Vida me dá prazer / Vida é a luz do dia / Vida vivida / Vida é o amor / Vida é cor e confusão / Vida é som e paixão" (GIL, 2019).

$\mathrm{Na}$ vida, não podemos esperar que as pessoas saiam de suas casas, se encontrem e entrem em um consenso de imediato.

As pessoas que chegam, chegam com todas as suas contradições, seus acúmulos, sua cultura, suas manias. As cheganças não são como uma amálgama de liga metálica que se retorce e se arranja a todo e qualquer custo. Na realidade, elas são mais como o encontro entre dois rios, como o Rio Negro e o Solimões, ou como as águas do rio quando encontram o mar no remanso.

Aos poucos elas se misturam, mas não de imediato.

Para que continue existindo vida - para "além da lógica do capital" (MÉSZÁROS, 2005) - é preciso que existam espaços como esses, pois eles carregam em si uma potencialidade de subversão e contra-ataque à hegemonia do capital. 
Sarau Palavra Encantada no Bar Cantinho Girassol: um espaço cultural na...

\section{REFERÊNCIAS}

BRANDÃO, C. R. O meio grito: Um estudo sobre as condições, os direitos, o valor e o trabalho popular associados ao problema da saúde em Goiás. In: BRANDÃO, C. R. (Org.). Pesquisa participante. São Paulo: Brasiliense, 1983. p. 130-198.

BURGOS, R. Periferias Urbanas: O chão dos catadores no urbano periférico. São Paulo: Humanitas, 2013.

BURGOS, R. Pesquisa qualitativa: Reflexões Geográficas a partir de um estudo de caso sobre as contradições urbanas da cidade de Sorocaba-SP. GeographiaMeridionalis, Pelotas, v. o1, n. o1, p. 145-159, jun. 2015 .

CARLOS, A. F. A. A Cidade. São Paulo: Contexto, 2013.

CANTO, C. Poesia na Periferia. Revista Raça, Sorocaba, out. 2016. Disponível em: https:// revistaraca.com.br/poesia-na-periferia/. Acesso em: 11 mar. 2019

GIL, Gilberto. Vida. BEST OF SAMBA vol. 1: Gilberto Gil, Gal Costa, Obina Shok. UK: Church Lane, 2019. 1 CD (52 $\mathrm{mim})$.

LE GOFF, J. Por amor às cidades: conversações com Jean Lebrun. São Paulo: UNESP, 1998.

LEFEBVRE, H. O Direito à Cidade. São Paulo: Centauro, 2001.

LEFEBVRE, H. A Revolução Urbana. Belo Horizonte: Ed. UFMG, 1999.

MARX, K; ENGELS, F. O Manifesto do Partido Comunista. São Paulo: Boitempo, 2005.

MÉSZÁROS, I. A educação para além do capital. São Paulo: Boitempo, 2005.

NASCIMENTO, É. P. do. É tudo nosso! Produção cultural na periferia paulistana. 2011. Tese (Doutorado em Antropologia) - Faculdade de Filosofia, Letras e Ciências Humanas, Universidade de São Paulo, São Paulo, 2011.

OLIVEIRA, M. A. N. de. Sarau Palavra Enacantada no Cantinho Girassol: Um espaço cultural na periferia da cidade de Sorocaba. 2016. Dissertação (Mestrado em Educação) - Centro de Ciências Humanas e Biológicas, Universidade Federal de São Carlos, Sorocaba, 2016.

ROLNIK, R. O que é Cidade. Brasiliense: São Paulo, 1988.

THOMAZ, Omar Ribeiro. A Temática Indígena na Escola: Novos subsídios para professores do $1^{\circ} \mathrm{e}$ $2^{\circ}$ graus. Brasília: MEC/ MARI / UNESCO, 1995.

\section{SOBRE OS AUTORES}

Marco Aurélio Nunes de Oliveira, Professor da Rede Pública Estadual de São Paulo e do Centro Paula Souza. Leciona na discplina de história. Formado desde de 2013 pela UNISO e Mestre em Educação pela Universidade Federal de São Carlos. E-mail: prof.marco.nunes@gmail.com.

Dulcinéia de Fátima Dulce Ferreira, professora Adjunto IV da Universidade Federal de São Carlos (UFSCar - Campus Sorocaba). Pós Doutorado em Cultura Popular junto à Universidade Federal do Maranhão (UFMA). Doutora (2006) 
e Mestre (1999) em Educação pela Universidade Estadual de Campinas - SP (UNICAMP). Pedagoga pela Faculdade de Filosofia Ciências e Letras de MoemaSão Paulo - (1988). É líder do Grupo de Pesquisa Educação, Comunidade e Movimentos Sociais (GECOMS - UFSCar - Sorocaba) e participa como colaboradora do Grupo de pesquisa Tecnologias e processos de subjetivação (UNESP - Rio Claro - SP) e NuRuNI (Núcleo de Extensão e pesquisa com populações e comunidades Rurais, Negras Quilombolas e Indígenas- UFMA). Realiza trabalhos de Ensino Pesquisa e Extensão vinculados ao Departamento de Ciências Humanas e Educação (DCHE) e ao Programa de Pós Graduação em Educação (PPGEd - Campus Sorocaba). Eixos temáticos: Educação, política e processos de subjetivação, Educação Popular, Cultura Popular e Processos Educativos; Educação de Jovens e Adultos, Educação como Prática da Liberdade.

E-mail: dulceferreira@ufscar.br.

Kelen Christina Leite, possui graduação em Ciências Sociais pela Universidade Federal de São Carlos (1994), mestrado em Ciências Sociais pela Universidade Federal de São Carlos (1998), doutorado em Ciências Sociais pela Universidade Federal de São Carlos (2005) com estágio doutoral em Economia Civile pela Università Degli Studi di Milano-Bicocca (2003-2004). Atualmente é Professora Associada da Universidade Federal de São Carlos, no Departamento de Ciências Humanas e Educação - DCHE e pesquisadora dos Grupos de Pesquisa: Trabalho, Organização Social e Comunitária e do grupo Educação, Comunidade e Movimentos Sociais. Tem experiência na área de Sociologia, com ênfase em Sociologia Econômica e do Trabalho atuando, principalmente, nos seguintes temas: Trabalho, Economia Solidária, Economia Civil, Estado, Mercado, Movimentos Sociais. Diretora do Centro de Ciências Humanas e Biológicas (CCHB) da UFSCar de 2013-2018. E-mail: kelen.leite@ymail.com.

Recebido em 22 de abril de 2019 e aprovado em 18 de novembro de 2020. 